\title{
A test of our humanity
}

\author{
Navjoyt Ladher clinical editor, The BMJ
}

Last week UK newspapers carried reports from the Greek island of Kos, with anguished British tourists complaining about their holidays being spoilt by Syrian refugees fleeing to the island and declaring they would go elsewhere for their summer break next year. If the reaction from these holidaymakers has you wondering about our compassion, the Australian government's response to the migrant crisis makes for grim reading.

As part of Australia's "stop the boats" policy, people arriving by boat in Australian waters are moved to offshore immigration detention centres on Pacific islands. Healthcare workers have described conditions in these centres as "appalling," with reports of substandard medical care, abuse of children, and unhygienic accommodation. As Michael Woodhead reports from Sydney this week (doi:10.1136/bmj.h3008), under new legislation enacted as part of the policy doctors face two years in jail if they raise concerns about mistreatment of asylum seekers in detention centres. Barri Phataford, co-founder of Doctors for Refugees and a GP in Sydney, said, "This policy is a fail on every level. Not only does it clearly compromise the safety and health of those in detention, it puts Australian registered doctors in an ethical and legal conflict."

In an editorial this week David Berger and Kamran Abbasi call for moral leadership from Australia and other western democracies in their treatment of refugees (doi:10.1136/bmj. h2907). Berger and Abbasi look to the past and warn that turning a blind eye to the plight of refugees doesn't make these problems go away: "They only get worse and eventually blow up in violent and entirely predictable ways, as the deaths of millions during the second world war and subsequently attest."

What is needed from politicians? "Moral leadership and global statesmanship must supplant a self interested, parochial political agenda ... The health and welfare of refugees is a test of our humanity, a test that we are failing once again."

In the UK, health leaders' plans to implement seven day working and to save $£ 22$ bn through efficiency measures are under way. In a new briefing the Nuffield Trust has highlighted the problem of staff burnout in the NHS and urged the government to prioritise "reconnecting with the NHS workforce and ensuring staff feel valued in their work," as Gareth Iacobucci reports (doi:10.1136/bmj.h3004). The trust also cautioned the NHS to reduce its reliance on agency staff, noting an $£ 800 \mathrm{~m}$ increase in spending on contract and agency staff in NHS hospital trusts in the past financial year. Simon Stevens, chief executive of NHS England, said in an interview with the BBC's Andrew Marr that tackling overspending on agency staff was important. Jeremy Hunt has pledged to cap total agency staff spending for each NHS trust in financial difficulty. As Hunt begins his second term as health secretary, Nicholas Timmins speaks to 10 previous holders of the job (doi:10.1136/bmj.h2954) and asks: what's the role of a health secretary anyway? Views are mixed. Some have come to office at a time when policy reform was needed, while others have stewarded the NHS through steadier times. As Virginia Bottomley put it, "Sometimes you want a window breaker and sometimes you want a glazier." All agreed that ministers should not be involved in the day to day management of the NHS, but opinion varied as to how far ministers were distanced from operational issues.

Does staff burnout count as an operational issue? Perhaps not, but it is hard to see Hunt's ambitious plans for the NHS getting far without attention to the wellbeing of the NHS workforce.

Cite this as: BMJ 2015;350:h3031

๑๑ BMJ Publishing Group Ltd 2015 